\title{
Female Representation in Chinese Otome Games: Comparative Research on Three Famous Games from 2017 to 2021
}

\author{
Yining Huan ${ }^{1, *}$
}

\author{
${ }^{1}$ Faculty of Humanities and Social Sciences, International Communication Studies, University of Nottingham Ningbo \\ China, Ningbo, 315154, China. \\ *Corresponding author. Email: hnyyh7@nottingham.edu.cn
}

\begin{abstract}
Otome games is a kind of love simulation role-playing games, which are originated in Japan. This genre first became widely popular throughout China in 2017 when Love and Producer was released by Papergames. Gender representation in otome games could have potential influence on female players, such as impact on their attitudes towards appearance and female role in gender relationship. This research does comparative research on female representation of the heroines in Love and Producer (2017), Tears of Themis (2020) and Light and Night (2021), which are three most popular Chinese otome games in recent years. This could help both the players and manufacturers to understand the construction of female characters in relation to their gender implication. The research finds that although female representation in Chinese otome games has improved a lot, there is still some gender stereotypes. There is an improvement on the representation of female characters in recent years regarding the increasing female images in academic and work fields. All three heroines are portrayed as well-educated white collars with their dream jobs, and the latter two games emphasize more on their occupational representation. This may because women engage more in the labor market and fight for their financial independence in China in the recent decades. Furthermore, it shows a growing trend of diverse female images. However, the overall style of their appearance and dressing tends to be sweet and innocent, which reflects traditional gender norms in patriarchal society that women are better to be sweet and obedient. Finally, the three heroines are most attractive for their nice and kind and lacks other personal traits and most of their personality are constructed simply through labeling.
\end{abstract}

Keywords: Female, Otome game, Gender stereotype

\section{INTRODUCTION}

Games are an important part of Chinese entertainment industries and there has been a growing number of female game players in recent year so that female orientation games have become a center of attention. According to the 2019 China game industry report released by the game industry committee, the number of female users has exceeded 300 million, nearly half of the total number of domestic game users, and marketing revenue was 52.68-billion-yuan, accounting for $22.8 \%$ of the total revenue. Nowadays, many games are produced to market at female users, and among them, otome games are the most popular one in China. Otome games, originated in Japan, are storybased dating simulation role-playing games that are targeted towards women. The goal of the games is that by acting as the heroine, players need to start a story line and develop a romantic relationship between the heroine and one of the several male characters. This genre is famous for its beautiful set painting, attracting narrative and popular voice actors. The first otome game is Angelique that released in 1994 by Koei in Japan, which was surprisingly well accepted across the country at that time, after which otome games are mostly established in Japan and formulated a kind of subculture.

Regarding Chinese otome game, it first gained large attention when Love and Producer released by Papergames company in 2017 and soon attracted a large number of female gamers, which became an overnight sensation. The game has 7 million downloads, 90 
percent of which are women and $57 \%$ of which are players of 20-24 years old [1]. This has driven the development of female mobile game market. After the big success of Love and Producer, many large game manufacturers have launched this genre of games in recent years. miHoYo released Tears of Themis in July 2020. This game is about the NXX investigation team, made up of the heroine who is a lawyer and four male protagonists, working together to resolve bizarre commissions and restore the truth. Night and Light was released in June 2021 by the largest Chinese game company Tencent Game. It is a highly immersive interactive love simulation game. The story is between the heroine who is a new fashion designer and five male protagonists, who are business elite, top fashion designer, childhood sweetheart, finance, and racing car driver respectively.

\section{LITERATURE REVIEW}

There have already been many researchers employing content analysis to study female representation in video game. Many studies found that female figures were constantly proved to be far less portrayed than males, often acting as hypersexualized subordinated characters [2]. For example, Bristot et al. did research on 12 female characters and found that negative stereotyped and hypersexualized female figures with low engagement in the narrative tended to be deviated from the proposed context, which implied the tendency of game producers to exclude female players [3]. Additionally, by analyzing female characters in 571 game samples released between 1983 and 2014, Lynch et al., concluded that although there was less sexualization than there was in the 1990s, most female characters were still secondary roles with more sexualized features than main characters, and the more sexualized female characters were, more capabilities they had [4]. Provenzo (1991) focused on 124 human figures on 47 covers of Nintendo's boxing games and discovered that $92 \%$ were males while $8 \%$ were female, $24 \%$ male were in the dominant position, and $33 \%$ female were in the submissive pose against no male doing this [5]. However, most of the research above chose to adopt content analysis. This is significant because as a quantitative research method, content analysis that contribute to the portrayal of female tends to be limited in answers of general level [8].

It should also be noticed that situations are gradually improving. Xeniya, who interviewed 2 experts in game design and collected results of the questionnaires from 234 video game players (mainly males) around the world, argued that the representations of female in various genres of video games were changing, from sexually seductive stereotyping characters to more independent and powerful ones, albeit slowly [6]. According to Engelbrecht (2020), Lara Croft, who is the female protagonist of a famous videogames Tomb Raider, could be regard as "a representative of femininity in contemporary popular culture". Lara is a powerful "Supergirl", displaying a female role model in early $21^{\text {st }}$ century both positively and negatively. She is a kind of "archetype" that represents "pervasive postfeminist portrayals of women", and many heroines in other videogames mimic and follow Lara's representation of women [7]. From a content analysis on the introductory films of 12 selected videogames, Jansz and Martis (2007) explored the tendency of Lara Phenomenon, which refers to "the appearance of a competent female character in a dominant position". They found that female characters presented the same leadership status as male characters in recent games, though appearing in a hypersexualized way. They also found that none of the female characters in the 12 games they selected were submissive, and some even dominated male characters, such as Jennifer in Primal, who was trying to save her boyfriend, which implied her higher power position [8].

Female game users were a longtime marginalized group, however, with the rise of popularity of female video gamers in recent years, some scholars have carried out research about female orientation games. When it comes to China, comparing to the lack of female representation in games in the past, there is indeed an improvement in the representativeness of female figures. However, it could be argued that the massive use of female roles in online games does not mean the improvement of women's status, but the collective unconscious gender discrimination against women formed under the combined influences of conservative ideology, patriarchal society, commercial environment catalysis, and male desire for domination [9]. Sun (2018) argues that there are three gender stereotypes of Chinese female players in game culture, which are silent NPC in male-dominant games, prosumer of Boy-love culture, and active consumer in otome games [10]. Furthermore, research on otome games generally focus on identification in game interaction and fan participation, such as emotional labor. For example, explore how companionship and protective emotional compensation are constructed in otome games and how otome culture redistribute as a form of subculture among audiences [11].

Although there are many research studies female representations in video games, there are still some research gaps. Most of the research studied female representation in games in general. Studies on otome games are limited in number, and most of them are from the perspective of fan culture and gender representations are not focused on. Since otome games are the most popular video games among female game players and players act as the heroine to play the game from the first point view, the representations of female characters, especially the heroine, have large possibility to 
influence the players. For example, the gender stereotypes affected by traditional gender norms embedded in otome games could negatively influenced female players. Furthermore, most of the existing research on otome games are about Japanese otome games and there is little study about Chinese otome games. This then gives importance to studying the representation of female characters in Chinese otome games. This could help not only game players, but also game manufacturers pay more attention to the significance of gender representations in otome games and other games. Moreover, the research can also help game manufacturers to understand their characters in relation to gender and be more cautious when building characters and narrative. In order to achieve the expected purposes, this research will deeply explore and evaluate gender representation of heroines in Chinese otome games and do comparative research on Love and Producer (2017), Tears of Themis (2020) and Light and Night (2021), which are three of the most popular otome games in China.

\section{RESULT \& DISCUSSION}

Normally, love simulation games, including galgames and otome games, intentionally try to weaken the sense of existence of protagonists in order to enable games to be more immersive. This is because by the lack of existence of protagonists, players could feel more as though they were the hero/heroine and take more control of the character. However, even in the limited representation of heroines in the Chinese otome games, some critical issues could still be found. According to the constructivist approach, representation is a practice, using material objects and effects, in which a sign signifies concepts and conveys meanings through its symbolic function [12]. Female representation in games, therefore, as a sign, conveys its symbolic meanings, which are constructed by the society. Through analyzing the representation of three heroines in Love and Producer (2017), Tears of Themis (2020) and Light and Night (2021), traditional gender norms embedded in patriarchal society can be revealed and gender stereotypes could be found in various aspects. According to Hall (1997, p. 247), stereotyping refers to simplifying and exaggerating people into a few simple essential features, which are memorable, easily grasped and widely recognized [13]. There are many similar traits of the three heroines, which are somewhat stereotypes of women. The following section will deeply discuss them through the perspective of appearance, background information and personality.

Regarding to appearance, all three heroines are very beautiful and attractive. As high immersive love simulation games, rather than blur or cover the heroine's face, Chinese otome games choose to construct a concrete character, and unlike galgames, in which the heroes are often an ordinary person, who has ordinary appearance, Chinese otome games emphasize beauty of women. Although when designing the heroine of Love and Producer, detailed appearance is deliberately weakened, using the image of a "girl next door" who has popular fringe, shawl hair, big eyes, and sharp face [14], she was still the campus belle and received many love letters in high school. This may because due to the traditional gender norms, society has higher expectation and requirements for women's appearance. Furthermore, all three heroines have the same facial characteristics of big eyes, small nose, and sharp face, similar hair style that is fringe and brown shawl hair as well as slim body figure. This also reflects the requirement of female appearance under the public aesthetic as Lynch points out that signs are inserted in a culturally constructed text, with a certain socio-cultural background that has its relation to the contained meanings. [16]. Those traits could convey certain expectations of women in the Chinese context. For example, big eyes, small nose, and fringe signify sweetness, while shawl hair signifies mild, wellbehaved classy lady. According to the traditional social norm, women are expected to be docile, mild and women full of characteristic tend to be severely judged by others.

In terms of dressing styles, the clothes heroines wear in these three games are overall sweet and pure, and there is a growing tendency to put more emphasis on portraying the appearance and showing profession related to the heroines' occupation. The heroine of Love and Producer wears a simple blue-and-white striped shirt with a white sling dress inside. The color of white conveys a sense of purity and innocence, while long dress and the bow at the waist indicate sweetness and elegance. She wears almost no makeup and there are no more fashion accessories except a simple pendant necklace. The character setting of her is a 22-year-old female white collar. The simple, innocent, elegance and sweet figure therefore is a representation of the average young women who has just entered the workplace.

In comparison to Love and Producer, the following two games has changed a lot in portraying the heroine's clothing. After 3 years, in Tears of Themis, the heroine's identity as a lawyer is emphasized throughout the game, even in the dressing style. As a young lawyer, she wears more formal clothes. In daily life, she wears white shirt with lace embellished, black bow tie, red blazer and black high-waisted A-line skirt that is side slit with yellow pleated skirt inside, which are professional and formal but not dull due to the sweet and cute decorations. When appearing in court, she wears gray suit, dark red head rope, bow tie, ear studs and sleeve studs. The color of grey and dark red signifies calm and profession. Wide use of red also echoes with wild rose, which is her code name in NXX teams. In the Chinese poems, wild roses often have the quality of strong will 
because they have tenacious vitality. The high ponytail and glasses also indicate ability and profession. Similarly, in Light and Night, as a fashion designer, the heroine has better taste in clothes and the clothes she wears are more fashionable and exquisite. The game put more emphasis on the appearance of the heroine and players can choose clothes, accessories, and makeup for her. The default dressing is a nice white shirt, sky blue bow tie and black A-line bull-puncher skirt, which is sweet and pure but comparatively formal. It is worth noting that the game has a lot of replaceable clothes and makeup for the heroine, which enriches the diversity of appearance. For instance, the neat short hair is rather fresh, which brings a new representation in the massive gentle long hair images of young women. Elaborate makeup and accessories can also be found. However, in general, the styles tend to be sweet, and pink is used a lot in the clothing.

The reason of changing from a simply sweet and innocent young woman into a more professional image of female white collar may be due to the increasing female representation in workplace in China. There is a trend of increasing engagement of women in labor market in urban China. Since 2003, Women's labor force participation (WLFP), an indicator portraying the economic role of female, in China showed an increasing trend due to the institutional transformation (marketization), the change of policies from the central government and the drastic rise of living cost in urban area in different periods [18]. Comparing to the past, more and more women enter in workplace, and they fight for financial independence, especially in urban city. Furthermore, due to commercial factors, the target consumers of Chinese otome games are young female white collars in their early twenties in first to third tier cities. Most of Chinese otome games do not open to users under 16 years old, and Light and Night is the first Chinese Otome game only open to people over 18 years old as in the Chinese context, students are not encouraged to or even not permitted to establish a romantic relationship in school. This is also because they have higher spending power than students. Therefore, when designing the heroines, companies tend to construct an image of white collar and beautify them, which can closer the distance between players and the heroine. It could be seen that the latest two games emphasize more on the appearance of the heroines as they both have make-up and more detailed clothing. On one hand, it reflects the improvement of the diverse female representation in the mass media, including professional images and cool girl. Furthermore, it shows that female white collars have the freedom and ability to dress up nice and decent, and live a delicate life in the urban city. On the other hand, this reveals the tendency that in digital media, images of beautiful women are more and more prevailing, and they become one of the products that media wants to sell in order to attract more users. The massive sweet female figures may tell girls to be tamed and docile in the patriarchal society.

The portrayal of heroines in digital games could sententiously influences players. Although the three games show a growing tendency that figures of heroine are professional according to their different occupations, all those three characters represent beautiful female white collars with pure femininity, such as innocence and sweetness. As Hodkinson argues, even if it is a story about professionally successful women, the need for women to be good-looking and attractive to men is still existing. [15]. The beautiful appearance and dressing of those heroines could reflect gender stereotypes that women should be charming and attractive in appearance and being sweet and innocent is what the pubic expect young women should be. This kind of representation appears frequently and is often stressed in media, which may cause the lack of diversity in public aesthetic culture. Due to the impact of digital media, the cultural standards of the ideal female beauty have already been changed over the past decades, including the thin bodies and facial features of big eyes and sharp face are all influenced by the wide speaf of western aesthetic [17]. So called ideal female figures are frequently appeared in adverts, social media, tv, films, and games, which has changed the women's view of themselves gradually. Digital games play an important role in shaping and influencing beauty standards subconsciously, especially otome games may covey the meaning that only the beautiful women can have the opportunity to find the true love. This may result in too much emphasis on appearance, and even do harm to both physical and mental health of women. The increasing consumption of beauty products, cosmetic surgery and diet industries in China indicates that young women encounter large social pressure to conform to the contemporary standards of the female ideal beauty [17]. By consuming media, it is likely for consumers to shape a kind of beauty-appreciation which are extreme and unhealthy and appeal to the standardized beauty portrayed in media. For example, there are several waves of appealing to orthogonal shoulder, elf's ears, A4 waist, many girls use unscientific fitness methods, do cosmetic surgeries and excessive dieting, which are harmful to their health. Those standards of beauty appear frequently and repetitively in digital games, even in otome games, which are games that are targeted at women. A large number of female players consume the games, and it is probable that they may change their self-identification and gradually be accustomed to those stereotypes.

Additionally, in terms of the background information of the three characters, there are also similarities. The three heroines all born in a nice and rich family and live alone in a nice apartment in the urban city. They all graduated from a famous university with outstanding academic performance, and now they 
have their dream job. In Love and Producer, the heroine's father was a program company owner and a producer of a popular tv show. The heroine graduated from the best university in the city as a top student. After her father's death, she has inherited the company and she is in charge of the company and the main tv program. Similarly, in Tears of Themis, the heroine's parents are biopharmaceutical researchers. She graduated from the best university in the faculty of law with excellent academic performance, the second highest in the graduating class. Now she works at one of the best law offices. Similar to the previous two protagonist, heroine in Light and Night is a new fashion designer just graduated abroad and came back to China to participate in the designer competition. She led out of thousands of designers and won the runner up, after which she entered the well-known garment manufactory. It could be seen that all heroines have excellent academic performance and a very decent job. This to some extent shows the increasing status of women in academic field and workplace. According to the theorists of patriarchy, males are perceived as ruling class and having controlling access to institutional power, while females are institutionally and economically dominated by males in the patriarchal society [19]. In the past, most Chinese women are not allowed to work because they must do household, and workplace was dominated by men. Specially in the top areas, there was few female figures. Due to several feminist waves and the rise of female status, more and more women could have access to school and work. They could then have the opportunity to pursue their own dreams. The images of female workers with high education and decent jobs may have positive influence on female players.

The last section will discuss the personality of the three heroines. It could be observed that the most remarkable characteristic of the three heroines is nice and kind, and they all have a dream and work hard to realize it, seeking justice with their holy thoughts and firm beliefs. However, apart from that, nothing could be found in their characteristics. There is a lack of personality of heroines, especially in Love and Producer and Light and Night, which could represent most Chinese otome games. Most words and sentences the heroine says serves for advancing the plot. The heroines' mental activities are also very descriptive. This means that they are always the description of the situation and the implication of the situation rather than true phycological activities of a human being. This is again probably because by doing this, the game may become more immersive to the player. However, the lack of personality makes these two heroines not like smart women as what has been described in the background information because what they do does not match their intelligence as they are high-educated women with a very good job. The lack of content shaping in the characterization leads to the intellectual quotient and emotional quotient of the heroines very unstable throughout the narrative. It seems that the heroines lack basic ability of judgement and problemsolving when they are in danger. For example, many times in Love and Producer, the heroine knows there would be danger but still chooses to go impulsively and put herself in a very dangerous situation again and again so that she always needs the four male protagonists to save her. In comparison, in Light and Night, the heroine becomes smarter as there is less situation where she needs protection, but some plots still seem a bit abrupt. When the heroine wants to rent an apartment, she is easily taken in by the agent, and it is Lu Chen who is one of the male protagonists that reminds her in time to avoid her cheated. The design is to highlight the calm and reliable character of the hero to make his image more attractive. However, this results in a negative image of the heroine that she always needs to be protected by male characters. These two games are very likely to show the charm of the heroes by letting them to save and protect the heroines.

In addition, in order to construct and fully present charming and active heroes, heroines in both Love and Producer and Light and Night, tend to be portrayed as very passive in gender relationship. It is always the male characters that do something to close the distance between them. The reaction of the heroines tends to be passive acceptance as they usually respond very short sentences and respond with a blush or pout, which enables the male characters to take in charge of their conversation or action. It seems to be reasonable because otome games need to put much emphasis on male characters than the heroine legitimacy because the male characters can bring much more profits to the company. However, this reflects gender stereotypes that women need to be protected by man and they are passive in gender relationship. This is influenced by conventional gender roles and the long-time patrilineality in the Chinese society. In the traditional Chinese family, "the norm of the male-centered line of descent" gives more power, responsibility, and recourses to the elder and/or male members in the family and women's role are often complementary, such as facilitating the productivity her husband [20]. In this case, males are often the ones to make decision for the family, while female members tend to be obedient and passive in the traditional gender norms. Gender representation in this way appearing frequently in digital games may reinforce this kind of gender stereotypes and have negative influences on players.

In contrast to Love and Producer and Light and Night, Tears of Themis has made a breakthrough in the characterization of the heroine. The heroine in Tears of Themis has a comparatively high sense of presence than the other two games, with a clear and strong personality. Rather than tell the players by simply labelling the 
heroine as smart and highly educated, this game indeed depicts her strong ability to work and solve problems throughout the narrative. To enable the game to be more immersive, players can deduce cases and find out the truth, exposing the darkness hidden in society, together with the heroine. Through her attitude towards work and fear of being questioned about professionalism, players could see that she is passionate and fully devoted to her job as a lawyer. For instance, she says "my lover is work", which emphasizes her passion and hints her dullness in romantic relationship. She is also very independent and do not rely on others, even the male protagonists. Her strong ability and will enable her not to be protected and saved by males all the time, rather, she can save the male protagonists in danger. This reverses the traditional female representation of always being protected and constructs an independent and powerful image of contemporary young women. According to Novak [21], role-playing games (RPG) as a genre has its advantage of developing a powerful female character because it has the nature to facilitate a heroic journey, where the character can fight and grow to be a hero, with a noble mission of "saving the world". Otome games, as a kind of RPG, often endow the heroine with such a mission, which could provide much space to create a diverse and live female character. Therefore, it is important to take good advantage of the narrative and work hard to construct positive and powerful female representation.

However, there are still some aspects need improvement. Although the heroine in Tears of Themis has diverse personality, there is still a lack of multidimensional complex mental activities. The heroine has a very strong sense of justice; however, it seems that the justice she believes is so absolute that it makes her seem somehow inhumane. The game creates characters through labeling and deepens the characters through deepening labels. The heroine is labeled as justice, and she is often filled with senses of selfrighteousness, ignoring warm humanity. There is too much emphasis on the pursuit of justice, which enables her to be mechanized to some extent. This has aroused fierce controversy. Some players consider the heroine is too strong a personality, making the game less immersive, and the loving experience is decline. It should also be noticed that after Tears of Themis (2020), Light and Night (2021) has a tendency of retrogression in the depiction of the heroine. This may be due to the controversy brought by Tears of Themis. The heroine with strong personality is not well accepted by all female players and many of them merely want to experience romantic relationship with handsome heroes in otome games. However, Light and Night (2021) puts more emphasis on the heroine's career than Love and producer (2018). As the first phenomenal Chinese otome game, Love and producer (2018) follow the route of traditional love simulation games, in which all the plots are based on the function of establishing romantic relationships. In comparison, the latter two games have their own unique focus, trying to make a breakthrough in a new direction. Tears of Themis focus on investigation and solving crimes so that it depicts more on the working ability of heroines, while Light and Night also focus on depicting the heroine's work and her best female friend has a strong sense of existence, showing that the heroine's life is not only around the male protagonists.

\section{CONCLUSION}

In conclusion, through comparative researching female representation of the heroine in three most popular Chinese otome games from 2017 to present (2021), it could be observed that overall, there is an improvement of female representation in Chinese otome games to construct more diverse and professional female images, however, stereotypes influenced by traditional gender norms still exist.

There is a growing tendency that Chinese otome games gradually put more emphasis on the portrayal of a professional heroine and the representation tends to be more diverse. Furthermore, all three heroines are depicted as a high-educated young woman who have a decent dream job. This may be due to the development of Chinese society and the promotion of gender equality, women's status in academic and work fields have been improved significantly. However, the three heroines' appearance is the same kind of beauty, and their dressing style are also the similar type, which is sweet and innocent. This not only reveals the higher expectation and requirement of female in the patriarchal society, but also shows that young women are expected to be sweet and docile under the public aesthetic. The massive sweet images may also result in pursuing the single aesthetic. In addition, there is a lack of personality in the three heroines. They are recognized almost nothing except nice and kind. Their personality of smart and independence are simply constructed through being labeled, such as high-educated, which cannot be seen through their behavior in the story. Especially in Love and Producer and Light and Night, the heroines are often portrayed as being protected by male and passive in the gender relationship, which reveals gender stereotypes that women are weak, and they should be obedient. Even if the personality of heroine in Tears of Themis is comparatively stronger and remarkable, her traits are still constructed through labelling and deepen the traits through deepening the labels, which leads to mechanization to some extent.

\section{REFERENCES}

[1] Wagner, Keith B., and Meng Liang. "Love and Producer as East Asian Transmedia: Otome Games, Sexless Polyamory, and Neoliberal Choice 
for Chinese and South Korean Young CareerOriented Women." Transmedia in Asia and the Pacific: Industry, Practice and Transcultural Dialogues (2021): 129-156.

[2] Near, C.E. Selling Gender: Associations of Box Art Representation of Female Characters With Sales for Teen- and Mature-rated Video Games. Sex Roles 68, 252-269 (2013). https://doi.org/10.1007/s11199-012-0231-6

[3] Bristot, Paula Casagrande, et al. "Female Representation in Video Games." Clei Electronic Journal 22.2 (2019).

[4] Lynch, Teresa, et al. "Sexy, strong, and secondary: A content analysis of female characters in video games across 31 years." Journal of Communication 66.4 (2016): 564-584.

[5] Provenzo, E. F. (1991). Video kids: Making sense of Nintendo. Cambridge, MA: Harvard University Press.

[6] Kondrat, Xeniya. "Gender and video games: How is female gender generally represented in various genres of video games?" Journal of comparative research in anthropology and sociology 6.01 (2015): 171-193.

[7] Engelbrecht, Janine. "The New Lara Phenomenon: A Postfeminist Analysis of Rise of the Tomb Raider." Game Studies 20.3 (2020).

[8] Jansz, Jeroen, and Raynel G. Martis. "The Lara phenomenon: Powerful female characters in video games." Sex roles 56.3-4 (2007): 141-148.

[9] Erzhen Chen, Yong $\mathrm{Xu}$, Female Images constructed by Online Games, Youth Reporter, $(2019 / 14)$

[10] Sun, J. "From Silent NPC to Active Consumer: Representing Female in Chinese Video Game Culture." (2018).

[11] Li, Z. Subculture and Emotional Compensation: Analysis of Otome's Game Mechanism. Media Criticism. (2019).

[12] Hall, Stuart. (1997b). The work of representation. In S. Hall (Ed.), Representation: Cultural representations and signifying practices (pp. 1-47). London: SAGE

[13] Hall, Stuart. (1997). The Spectacle of the 'Other'. In S. Hall (ed.) Representation: Cultural Representations and Signifying Practices. London: SAGE. pp. 225-290.

[14] Cheng. "Semiotics, self, ritual: study on emotional interaction of female gamer in otome game." (2020).
[15] Hodkinson, Paul. Media, culture and society: An introduction. Sage, 2016

[16] Lynch, O.M. (ed.) (1990) Divine Passions: The social construction of emotion in India, University of California Press.

[17] Jung, Jaehee. "Young women's perceptions of traditional and contemporary female beauty ideals in China." Family and Consumer Sciences Research Journal 47.1 (2018): 56-72.

[18] Wu, Yuxiao, and Dongyang Zhou. "Women's labor force participation in urban China, 19902010." Chinese Sociological Review 47.4 (2015): 314-342.

[19] Mirkin, Harris. "The passive female the theory of patriarchy." American Studies 25.2 (1984): 39-57.

[20] Hu, Yang, and Jacqueline Scott. "Family and gender values in China: Generational, geographic, and gender differences." Journal of Family Issues 37.9 (2016): 1267-1293.

[21] J. Novak, "Desenvolvimento de Games," Cengage Learning. p. 472, (2010). 